\title{
Pichia pastoris as a host to overexpress the thermostable T1 lipase from Geobacillus zalihae
}

\begin{abstract}
Pichia pastoris was known to be a good expression system in producing various heterologous proteins. The gene encoding thermostable Tl lipase from Geobacillus zalihae was cloned into pPICZ $\mathbf{I} \pm \mathrm{B}$ and expressed in P. pastoris strains (GS115, X-33 and KM71H) under regulation of alcohol oxidase promoter. The expression of the gene in Escherichia coli system showed low expression level. Therefore, this study would highlight on the overexpression of the T1 lipase in yeast extracellularly. Recombinant X-33/pPICZÎİB/T1-2 (XPB2),

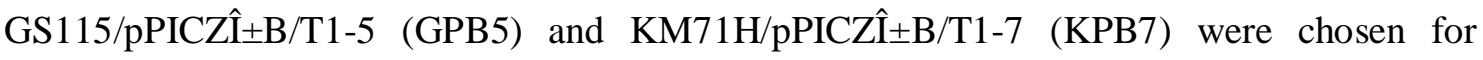
optimization in shake flask. Optimization strategies showed that these recombinants preferred YPTM medium with initial induction OD600nm $=7$ cell biomass and $2 \%(\mathrm{v} / \mathrm{v})$ methanol to provide optimal expression conditions. Hyper-resistant transformants at $3000 \mathrm{ug} / \mathrm{mL}$ zeocin gave better expression than $100 \mathrm{ug} / \mathrm{mL}$ zeocin selection. Time course study by using different inocula age showed that OD600nm $=7$ expressed lipase at the highest level. The highest expression level was attained with GPB5 $(88 \mathrm{U} / \mathrm{ml})$, XPB2 $(81 \mathrm{U} / \mathrm{ml})$ and KPB7 $(51 \mathrm{U} / \mathrm{ml})$. Western Blot analysis confirmed that the molecular mass of recombinant Tl lipase was 45 $\mathrm{kDa}$. In conclusion, thermostable $\mathrm{Tl}$ lipase was successfully overexpressed by using secretory P. pastoris system with two-fold higher than E. coli system.
\end{abstract}

Keyword: Expression; Geobacillus zalihae; Pichia pastoris thermostable lipase 